\title{
Global approaches to assessing, monitoring, mapping, and remedying soil pollution
}

\author{
Natalia Rodríguez Eugenio • Ravi Naidu • Claudio Massimo Colombo
}

Received: 31 July 2020 /Accepted: 31 July 2020 / Published online: 28 August 2020

(C) Springer Nature Switzerland AG 2020

The world's soil resources are subject to anthropogenic overexploitation exacerbated by environmental pressures caused by climate change and increasingly frequent extreme weather events. The latest estimates done by the Food and Agriculture Organization of the United Nations indicate that around one-third of the world's soils are suffering some degree of degradation. In addition, increased production, use and disposal of synthetic chemicals, and mobilization of trace elements and other raw materials by anthropogenic activities have loaded soils with a great variety and load of contaminants, such that they have become one of the largest environmental reservoirs of pollution. Thousands of different chemicals are used daily and global estimates indicate that the use of chemicals other than pharmaceuticals will rocket by 2030. Considering the current state of soil resources and

This article is part of the Topical Collection on Global Approaches to Assessing, Monitoring, Mapping and Remedying Soil Pollution

N. R. Eugenio $(\square)$

Global Soil Partnership, Food and Agriculture Organization of the United Nations, Rome, Italy

e-mail: Natalia.rodriguezeugenio@fao.org

R. Naidu

Cooperative Research Centre for Contamination Assessment and Remediation of the Environment (CRCCARE), University of Newcastle, Callaghan, Australia

e-mail: ravi.naidu@newcastle.edu.au

C. M. Colombo

Agriculture, Environment and Food Department, Università del

Molise, Campobasso, Italy

e-mail: colombo@unimol.it the trends in societal development and consumption of chemicals, it seems clear that soil pollution is and will be one of the greatest threats to environmental and human health in the coming decades.

Soils have the intrinsic capacity to retain, filter, buffer, and degrade organic and inorganic contaminants. This means that the presence of contaminants in the soil does not become evident until their concentration is such as to be harmful to ecosystems and humans, making it a hidden threat. Soil properties that control the fate of contaminants have a high spatial variability and can be modified over time by soil management practices. Similarly, the spatial distribution of pollution sources is highly variable and depends on human and environmental factors. The complexity of the soil matrix and the interactions between it, living organisms and contaminants, make it a challenging task to identify and quantify the various contaminants and the forms in which they are found, which will influence both their toxicity and mobility between environmental compartments. Not only is the evaluation of soil pollution and risk assessment a major challenge, but also its control and remediation is one of the major concerns of humankind. Soil pollution remediation techniques are often costly and technically complex, and continuous innovation is required to develop cost-effective and environmentally sound approaches.

The special issue entitled "Global approaches to assessing, monitoring, mapping, and remedying soil pollution" reflects some examples of the research presented during the Global Symposium on Soil Pollution (GSOP18) held at the Headquarters of the Food and 
Agriculture Organization of the United Nations (FAO) in Rome from 2 to 4 May 2018. This symposium was jointly organized by the FAO and its Global Soil Partnership, and the Intergovernmental Technical Panel on Soil, the Secretariats of the Basel, Rotterdam and Stockholm Conventions, the UN Environment, and the World Health Organization. The GSOP18 aimed to be a neutral platform to bring the best scientific information available on the status, trends, and actions (scientific, technical and technological, and political actions) on soil pollution at national, regional, and global level. The GSOP18 was a key action in the implementation of the Voluntary Guidelines for Sustainable Soil Management (FAO, 2017) and the resolution on soil contamination, adopted at the third session of the United Nations Assembly for the Environment (UNEA-3) (UNEP, 2017), with regard to the prevention and reduction of harmful substances in soils as a means of maintaining healthy soils and food security in accordance with the Sustainable Development Goals. The GSOP18 also served to set a global agenda for action focus on gathering scientific evidence, improving soil pollution data and information, and implementing action on the field to prevent and reduce soil pollution and remediate polluted sites.

This special issue contains five contributions on the assessment, distribution, and remediation of different soil contaminants that pose significant risks in different regions of the planet. The editors hope that this SI can be of use to young and experienced scientists to continue to improve our understanding of the complex processes that control the fate of contaminants in ecosystems, including soil, water, and plant interactions. This SI also aims to highlight different soil remediation techniques specific to different contaminants and thus motivate other researchers to continue to develop better, more environmentally friendly, sustainable, and effective methods of managing and remedying polluted environments.

Publisher's note Springer Nature remains neutral with regard to jurisdictional claims in published maps and institutional affiliations. 